\title{
Пандемия коронавируса и реакции в странах, вступивших в ЕС в 2004-2007
}

\section{Пал Дунай}

Европейский центр исследований по вопросам безопасности им. Джорджа К. Маршалла, http://www.marshallcenter.org

\begin{abstract}
Резюме: В этой статье представлена реакция на пандемию коронавируса стран Центральной и Восточной Европы (ЦВЕ), входящих в ЕС и НАТО. Понятно, что есть много общего, поскольку пандемия - глобальная проблема - затронула все государства региона, в целом одинаково. Географическое положение, размер (отсутствуют великие державы) и исторические традиции привели к тому, что воздействие пандемии на эти страны было, примерно, в одинаковом направлении. Можно заметить, что международные ориентиры этих малых и средних стран находятся в разных направлениях в зависимости от того, за какими другими государствами они следят и часто следуют, принимая решение о своих шагах в таком глобальном кризисе. Эта статья не может быть полностью исчерпывающей, поэтому основное внимание будет уделено реакции служб здравоохранения и чрезвычайных ситуаций. Возникает вопрос, являются ли какие-либо сходства детерминированными или есть заметные различия из-за разнообразия политических систем и текущей истории этих стран.
\end{abstract}

Ключевые слова: коронавирус, пандемия, Восточная и Центральная Европа.

\section{Введение}

Поскольку пандемия коронавируса нарушила повестку дня в области безопасности и приобрела приоритет в международной политике, в настоящее время изобилуют спекуляции о том, как долго продлится это изменение 
мира. Взгляды различаются: некоторые исходят из того, что пандемия - это не более чем икота, и через ограниченный период в несколько месяцев или максимум в два года мир вернется к «нормальному состоянию», особенно если вакцинация станет доступной для всего мира. Другие считают, что мы имеем дело с изменением парадигмы, и что мир вступает в новую эру. Эта статья занимает позицию где-то посередине и, хотя автор придерживается мнения, что мы не столкнемся с изменением парадигмы, в ней утверждается, что Covid-19 в большой степени будет способствовать усилению тех исторических тенденций, которые уже действовали какое-то время. Коронавирус не может изменить основных действующих субъектов международной политики или отвлечь внимание от стихийных бедствий и управления ими, а также не изменит характер международной системы, в центре которой находится национальное государство, и решающую роль отношений между основными действующими субъектами в мире в целом. ${ }^{1}$ В этой статье не поддерживается точка зрения о том, что и Китай, и США выйдут из кризиса с коронавирусом ослабленными, и что «результатом будет продолжающийся медленный, но неуклонный дрейф в мире к международной анархии». ${ }^{2}$ Независимо от того, какой сценарий будет преобладать, ясно, что державы второго ряда и более малые вполне могут иметь больше возможностей для выбора при принятии решения о своей ориентации и своей способности влиять на других участников. В порядке исключения, это также может оказаться мнимым выбором для государств в ЦВЕ. Однако есть все основания предполагать, что большинство этих государств не будут рассматривать какие-либо другие варианты и будут оставаться такими же приверженными к Западу, как и в течение последних тридцати лет.

Кажется очевидным, что диктатуры и автократические режимы, с одной стороны, и демократии, с другой, по-разному справляются с пандемией (как они обычно справляются с другими антропогенными или естественными кризисами). У них принципиальная разница во взглядах. Для демократий «кризис - это политическое испытание», тогда как для автократии «кризис это угроза легитимности режима». ${ }^{3}$ Это означает, что для автократий серьезный кризис является серьезным вызовом, который может привести к внезапной смене политической поддержки и, следовательно, поставить под

1 Richard Haass, "The Pandemic Will Accelerate History Rather Than Reshape It: Not Every Crisis Is a Turning Point," Foreign Affairs, April 7, 2020, по состоянию на 20 мая 2020, https://www.foreignaffairs.com/articles/united-states/2020-04-07/pandemicwill-accelerate-history-rather-reshape-it.

2 Kevin Rudd, "The Coming Post-COVID Anarchy: The Pandemic Bodes III for Both American and Chinese Power - and for the Global Power," Foreign Affairs, May 6, 2020, по состоянию на 16 мая 2020, https://www.foreignaffairs.com/articles/unitedstates/2020-05-06/coming-post-covid-anarchy.

3 Shlomo Ben-Ami, "Why Democracies Are Better at Managing Crises," The Strategist, May 20, 2020, по состоянию на 21 мая 2020, https://www.aspistrategist.org.au/whydemocracies-are-better-at-managing-crises. 
угрозу власть имущих. Для демократии это значит гораздо меньше, поскольку власть обычно не является вопросом политического (а иногда и экзистенциального) выживания.

Несмотря на эту дихотомию, необходимо принимать во внимание еще один фактор. Помимо пропасти между демократиями и автократиями (и очень немногих полностью диктаторских режимов, которые у нас все еще есть), это кризисное управление популистскими и непопулистскими лидерами. Лидеры-популисты обычно пытались преуменьшить важность проблемы и, следовательно, не выделяли своевременно адекватные ресурсы. Из-за этого они часто причиняли вред, в том числе рисковали жизнями своих людей. Однако, помимо этого, между демократиями и автократическими режимами существует еще одна большая разница. В то время как популистским лидерам демократических стран рано или поздно приходится столкнуться с открытым обществом, свободной прессой и политической оппозицией, что в большинстве случаев значительно уменьшает ущерб от их действий, ${ }^{4}$ автократы уже сделали политическую оппозицию виртуальной, и купили или напугали свободную прессу, тем самым устранив источники предотвращения вреда. Именно здесь озабоченность, четко выраженная в разгар пандемии, приобрела важность. Свобода прессы отступает, и согласно отчету Freedom House, опубликованному в разгар пандемии, «свобода СМИ ухудшается во всем мире за последнее десятилетие с появлением новых форм репрессий как в открытых обществах, так и в авторитарных государствах. Эта тенденция наиболее остро проявляется в Европе». ${ }^{5}$ Несмотря на то, что разница между демократиями и автократиями остается фундаментальной, каждая их реакция на кризис в значительной степени была окрашена популизмом.

В этой статье представлены и проанализированы реакции на пандемию коронавируса тех центральноевропейских и восточноевропейских государств, которые присоединились к ЕС в 2004 и 2007 годах. В ней представлены способы, которыми государства реагировали на кризис в области здравоохранения, и меры, которые они приняли для взятия ситуации и общества под контроль. Было бы легко предположить, что, поскольку представленные здесь страны, все без исключения, являются членами ЕС и НАТО, они должны были действовать аналогичным образом, и что они также будут делать то же самое в период восстановления и прогнозируемой второй волны пандемия. Однако ситуация более сложная.

4 Заметным исключением может быть Бразилия, где ущерб кажется длительным, а президент продолжает вести себя беспечно, несмотря на ужасающие данные и другие доказательства о потерях, понесенных бразильцами. Высказываются предположения, в какой степени человеческие потери повлияют на популярность президента в свете его популистских настроений.

5 Sarah Repucci, "Freedom and the Media 2019. Media Freedom: A Downward Spiral," Freedom House, по состоянию на 21 мая 2020, https://freedomhouse.org/report/ freedom-and-media/2019/media-freedom-downward-spiral. 


\section{Пандемия коронавируса: как справлялись с чрезвычайной ситу- ацией в здравоохранении}

Ни одно государство не могло быть полностью подготовлено к столь крупномасштабной проблеме здравоохранения, которая пришла в Европу с таким кратким предварительным предупреждением. Поэтому, когда мы рассматриваем реакцию различных стран, мы можем работать с относительными результатами и спрашивать, что каждая из них могла бы сделать лучше. Тем не менее, государства, чья реакция на пандемию коронавируса описана и проанализирована вкратце в данной статье, представлены как успешные на данный момент с меньшим количеством инфицированных людей и, в большинстве случаев, с меньшим числом умерших, чем во многих западных странах, где люди предположительно больше и лучше обеспечены услугами здравоохранения, чем в целом их более бедные соседи из Центральной и Восточной Европы (ЦВЕ). Возникает вопрос, как можно объяснить эти хорошие новости.

Пристального внимания заслуживают два набора данных - число выявленных случаев заражения и число умерших в результате коронавируса. В обоих случаях имеющиеся данные показывают, что в странах ЦВЕ числа значительно ниже, чем в более крупных европейских государствах, таких как Италия, Испания, Франция или Великобритания. За исключением Венгрии, число погибших невелико, а в некоторых случаях чрезвычайно мало. Причины этого можно найти не в количественном анализе, а при более близком рассмотрении региона.

Эти десять государств имеют ряд общих черт, как тех, что касается прошлого, так и тех, что касается настоящего:

1. В течение нескольких десятилетий эти государства были так называемыми социалистическими странами, в которых организация общества отдавала приоритет принятию и следованию правилам и повиновению. Хотя старый режим закончился почти три десятилетия назад и общества почувствовали вкус свободы, старые навыки остались, особенно у старших поколений. Поскольку пандемия больше всего угрожает этому поколению, их самодисциплина в следовании введенным мерам, таким как социальное дистанцирование, оставаться дома и не выходить на улицу без особой причины, а также ношение масок, безусловно, было частью этого относительного успеха.

2. Кроме того, есть еще один фактор, который требует научного анализа: уровень вакцинации в этих странах всегда был достаточно высоким, как в историческом плане, так и в настоящее время. Два примера - это числа вакцинированных бациллой Кальмета-Герена (БЦЖ) против туберкулеза в течение многих лет, и те, кто в настоящее время проходит регулярную вакцинацию от гриппа. Пока нет научных доказательств, но существуют многочисленные предполо- 
Таблица 1. COVID-19 в Центральной и Восточной Европе (1 июня 2020).

\begin{tabular}{|l|c|c|c|c|c|}
\hline & $\begin{array}{c}\text { Подтвер- } \\
\text { жденные } \\
\text { случаи }\end{array}$ & $\begin{array}{c}\text { Подтвер- } \\
\text { жденные } \\
\text { случаи } \\
\text { смерти }\end{array}$ & $\begin{array}{c}\text { Подтвер- } \\
\text { жденые } \\
\text { случаи } \\
\text { смерти к } \\
\text { числу } \\
\text { случаев } \\
\text { зараже- } \\
\text { ния (\%) }\end{array}$ & $\begin{array}{c}\text { Подтвер- } \\
\text { жденые } \\
\text { случаи } \\
\text { миллион } \\
\text { населения }\end{array}$ & $\begin{array}{c}\text { Ожидаемая } \\
\text { продолжи- } \\
\text { тельность } \\
\text { жизни }\end{array}$ \\
\hline Болгария & 2,519 & 140 & 5,6 & 20 & 75.0 \\
\hline Чехия & 9,286 & 321 & 3.5 & 29.9 & 79.3 \\
\hline Эстония & 1,870 & 68 & 2.75 & 55.3 & 77.4 \\
\hline Венгрия & 3,892 & 527 & 13.5 & 53.9 & 76.7 \\
\hline Латвия & 1,066 & 24 & 2.25 & 12.75 & 75.4 \\
\hline Литва & 1,678 & 70 & 4.17 & 25.6 & 75.5 \\
\hline Польша & 24,165 & 1,074 & 4.44 & 28.0 & 78.3 \\
\hline Румыния & 19,398 & 1,276 & 6.57 & 59.89 & 76.0 \\
\hline Словакия & 1,522 & 28 & 1.83 & 18.38 & 77.8 \\
\hline Словения & 1,473 & 109 & 7.39 & 51.84 & 81.4 \\
\hline Всего & 66,869 & 3,637 & 5.2 & - & - \\
\hline
\end{tabular}

Источник: Ресурсный центр по коронавирусу института Джона Хопкинса.

жения о положительном влиянии вакцины БЦЖ на сдерживание симптомов коронавируса. Можно считать само собой разумеющимся, что последует дальнейший анализ, чтобы увидеть, есть ли корреляция между ними не столько в отношении заражения вирусом, сколько в отношении серьезности симптомов и летальности исхода.

3. Существует также еще один исторический факт, который необходимо учитывать, а именно то, что во время своего коммунистического прошлого социалистические страны имели низкокачественные медицинские услуги как социальное благо с огромными ресурсами. Эти медицинские услуги по-прежнему слишком сконцентрированы в больницах, что является одной из тех характерных черт, которые Европейский Союз часто критикует. Такие мероприятия, как однодневные операции, обычно были недостаточно распространены, и даже сегодня больничных коек все еще слишком много. Если мы посмотрим на статистику, то вывод очевиден: «Венгрия (6-е место), Чешская Республика, Польша и Литва (с 7-го по 9е) - все входят в первую десятку стран мира с наибольшим количеством больничных коек на тысячу жителей, и Словакия (11-е место) 
следует сразу за первой десяткой». ${ }^{6}$ Таким образом, эта недостаточно радикальная модернизация здравоохранения сработала на пользу странам региона во время пандемии.

Откладывая в сторону исторические соображения, важно отметить, что население ЦВЕ по-прежнему имеет более короткую продолжительность жизни, чем многие из «старых стран-членов ЕС» или даже блудный сын ЕС, Великобритания. Среди 27 стран-членов ЕС, Словения с самой высокой продолжительностью жизни в ЦВЕ занимает 9-е место в ЕС, а другие страны значительно ниже в списке. Тем не менее, есть и хорошие новости: в течение последних двух десятилетий в этих странах увеличивалась продолжительность жизни. Столь благоприятные данные объясняются рядом причин. Качество медицинских услуг в странах ЦВЕ варьирует, но в целом доверие к их способности оказывать услуги в случае крупномасштабной чрезвычайной ситуации в области здравоохранения довольно низкое. Следовательно, у населения появился дополнительный стимул проявлять бдительность. Как сказал министр здравоохранения Чешской Республики: «Мы были уверены, что наши больницы не выдержат сложившуюся ситуацию. Мы должны были отреагировать». ${ }^{7}$ В итоге, были идентифицированы три государства, неспособных справиться с пандемией, если потребности в отделениях интенсивной терапии (ОИТ) и аппаратах искусственной вентиляции легких быстро увеличатся: Болгария, Венгрия и Румыния. Как сказала Вероника Ангел, в их ситуации «любое увеличение числа случаев опрокинет систему». ${ }^{8}$ У других стран было несколько меньше причин для беспокойства, но они столкнулись с другими проблемами, такими, как потребность в современном оборудовании и медицинском персонале.

Что касается медицинского оборудования, то страны региона осознали свои недостатки и начали импортировать все, что могли. Обычно это означало приобретение защитного снаряжения (масок и костюмов), оборудования для тестирования COVID-19 и аппаратов ИВЛ из Китая, хотя позже они также приобретались и из других источников. Чешская Республика показала

6 Данные о больничный койках отражают ситуацию в 2017. Bojan Pancevski and Drew Hinshaw, "Poorer Nations in Europe's East Could Teach the West a Lesson on Coronavirus," The Wall Street Journal, April 12, 2020, по состоянию на 16 мая 2020, https://www.wsj.com/articles/poorer-eastern-european-nations-could-teach-thewest-a-lesson-on-coronavirus-11586718779.

7 Dénes Albert, "Hungary, Poland and Other Eastern European Countries Are Faring Better with Coronavirus for These Reasons," Remix News, April 29, 2020, по состоянию на 16 мая 2020, https://rmx.news/article/article/hungary-poland-andother-eastern-european-countries-are-faring-better-with-coronavirus-for-thesereasons.

8 По мнению румынского политолога Вероники Ангел, которую цитировали Shaun Walker and Helena Smith, "Why Has Eastern Europe Suffered Less from Coronavirus than the West?," The Guardian, May 5, 2020, по состоянию на 16 мая 2020, www.theguardian.com/world/2020/may/05/why-has-eastern-europe-suffered-lessfrom-coronavirus-than-the-west. 
пример региону, первой отправив в Китай специальный самолет для перевозки оборудования. За ней последовали другие, затронутые пандемией, которые также поняли, что Китай может удовлетворять потребности, тогда как потенциальные поставщики в Европе испытывают нехватку оборудования. Хотя позже экспорт начали осуществлять и другие страны, в марте все еще имел место монополистический рынок. Другие страны-члены ЕС были заняты попытками решить свои собственные проблемы пандемии и в качестве защитной меры для удовлетворения своих внутренних потребностей ввели запреты на экспорт. Потребность в других европейских странах возникла одновременно с потребностями в странах ЦВЕ, поэтому зависимость от китайского импорта была отражением того факта, что Пекин находился на другой стадии пандемической кривой и там сложилось впечатление, что они уже преодолели кризис (что в некоторой степени было переоценкой). Позже некоторые страны ЦВЕ, а также некоторые государства, расположенные дальше на Запад, пришли к выводу, что материалы и оборудование, импортированные из Китая, были некачественными, и выразили свою неудовлетворенность. Однако их реакции были разными. Чехия была самой открытой, четко выражая свое мнение, что было нормальным в любой коммерческой сделке (как и Нидерланды), в то время как другие были более осторожны, а некоторые - довольно робки. Венгрия, например, удовлетворилась некоторыми двусмысленными заявлениями и высказала нечетко сформулированную озабоченность по поводу качества главному медицинскому специалисту вместо того, чтобы потребовать ответа от лица, более непосредственно связанного с правительством.

Что касается наличия медицинского персонала, многие страны ЦВЕ столкнулись с проблемой нехватки квалифицированного медицинского персонала, включая лечащих врачей. Это произошло из-за сочетания свободного передвижения рабочей силы в Европейском союзе с низкой оплатой труда в ЦВЕ для профессий, которые легко конвертируемы в международном плане. Странам ЦВЕ повезло, что полномасштабная пандемия не затронула их в полную силу. Таким образом, они не столкнулись с ситуацией, в которой они не смогли бы отреагировать из-за нехватки персонала. Конечно, помогли временная надбавка к зарплате и некоторые другие меры, такие как признание выдающихся усилий персонала в секторе здравоохранения. Однако этот кризис также выявил долгосрочные структурные проблемы. Остается открытым вопрос, извлекут ли эти государства уроки из этого опыта и введут ли долгосрочные меры для решения проблемы до возможной второй волны пандемии. Это потребует значительного увеличения ежемесячной заработной платы, чтобы медсестрам не пришлось выживать на 400 евро, а врачам - на 1200. Если это не изменится, отток профессионалов, который продолжается уже несколько лет, продолжится. ${ }^{9}$ И последнее,

9 По оценкам румынского министерства здравоохранения, между 2007 и 2018 43000 врачей уехало из страны. Смотри Shaun Walker, "Romanian Hospitals in Crisis as Emigration Takes Its Tall," The Guardian, April 21, 2019, по состоянию на 16 
но не менее важное: необходимо будет обучать больше медицинских специалистов. В некоторых случаях это уже начало делаться, когда несколько лет назад появились первые признаки эмиграции лиц из медицинского сектора. Однако, когда нехватка врачей достигает 50-60 процентов, лекарства нет. Большинство из тех, кто уезжает, делают карьеру в Западной Европе. Очевидно, что рынок некоторых из самых богатых западноевропейских государств - от Великобритании через Скандинавию до немецкоязычной части Европы - может продолжать поглощать новых профессионалов.

Понятно, что страны ЦВЕ, будучи более бедными, чем их более удачливые коллеги-члены ЕС, расположенные дальше на Запад, меньше тратят на сектор здравоохранения. Тот факт, что они также меньше тратят с учетом паритета покупательной способности (ППС), вызывает некоторое беспокойство. Однако разрыв между средними расходами по ОЭСР (3994 долл. США) и расходами в странах ЦВЕ не является значительным. Он колеблется от 3068 долларов (Чехия) до 1749 долларов (Латвия). ${ }^{10}$ Тем не менее, из-за высокой мобильности медицинских работников этому вопросу необходимо уделять должное внимание. В некоторых странах дополнительные расходы не приводят к существенной разнице, как следовало бы. Это связано с тем, что тендеры на закупку медицинского оборудования и материалов подвержены коррупции, и поэтому расходы растут без соразмерного повышения качества. Вместо того, чтобы скользить по поверхности проблемы, нужно искать ее корни.

Обобщая опыт, накопленный в результате реакции государств ЦВЕ на вспышку пандемии коронавируса весной 2020 года, можно сделать вывод, что хотя большинство государств имели дело с теми или иными недостатками, ни одно из них не имело дело с неуправляемой проблемой. Неизвестно, приведет ли такое «мягкое предупреждение» к дальнейшей приоритизации услуг здравоохранения, чтобы эти страны, как барон Мюнхгаузен, смогли бы сами себя спасти от беды. Трудности усугубляются тем, что в ЕС здравоохранение является национальной компетенцией, а это означает, что государства-члены не могут рассчитывать на большее, чем мягкое убеждение со стороны своих партнеров по ЕС, если не удастся достичь консенсуса по пересмотру правил.

В нескольких странах ЦВЕ (и не только там) было видно, что правительства не усвоили уроки, которые регулярно преподаются на учебных курсах

мая 2020, https://www.theguardian.com/world/2019/apr/21/romanian-hospitalsin-crisis-as-emigration-take-its-toll. Число врачей - экономических мигрантов значительно меньше, но они демонстрируют аналогичную проблему.

10 Расходы на здравоохранение на душу населения, 2018 (или ближайший год), OECD, "Health at a Glance 2019: OECD Indicators," Paris, OECD, 2019, по состоянию на 20 мая 2020, www.oecd-ilibrary.org/social-issues-migration-health/health-at-aglance-2019_4dd50c09-en. Нет сравнительных данных о Болгарии и Румынии, которые не являются членами ОИСР. 
по менеджменту конфликтов. Приоритет следует отдавать защите лиц, первыми принимающими ответные меры; в данном случае люди, работающие в системе здравоохранения. Второй по важности слой мер защиты должен быть направлен на наиболее уязвимых людей, например тех, кто живет в домах престарелых. Имели место множество жалоб в секторе здравоохранения, особенно на ранних этапах пандемии. Были небольшие скандалы в разных странах. Несколько сотен человек вышли на пенсию в Румынии, небольшая спонтанная забастовка разразилась в больнице в Венгрии, поскольку не было защитных костюмов, а маски не соответствовали соответствующим стандартам для медицинских работников. Шло время, поступали медицинские материалы, и организация распределения защитного снаряжения постепенно улучшалась.

Успешная защита от коронавируса также зависела от готовности разных стран учиться на примере других и быстро реагировать. Можно считать само собой разумеющимся, что при анализе этого кризиса будет установлено какое государство что узнало от какого партнера и какие государства стали «брэндом» в здравоохранении. По мнению российского политолога, «тест на вирус лучше всего выдержали те государства, которые не озабочены постоянным доказательством своей исключительности, но сосредоточены на создании безопасных и комфортных условий жизни для своих граждан». ${ }^{11}$ Так возможно обстоят дела и с многими странами ЦВЕ, поскольку они обычно являются государствами, принимающими политику или формирующими политику, и не имеют чрезмерного коллективного эго, которое мешало бы им быть готовыми к обучению. Что действительно способствовало успеху, так это то, насколько хорошо отреагировали политические классы и показали ли они пример соблюдения защитных мер. Особых сюрпризов не было, хотя одни государства определенно показали лучшие результаты, чем другие. Достаточно сказать, что Словакия преуспела по обоим пунктам. Она извлекла уроки из опыта Чехии, и таким образом, получила драгоценное время для реагирования на развитие пандемии. Изоляция началась своевременно, например, в Чехии за шесть дней до первой смерти от коронавируса. В Словакии, когда новый кабинет был приведен к присяге, в Братиславе все носили маски, а на инаугурации президента страны она ввела моду, чтобы маска гармонировала с ее платьем. В то время, когда так называемые страны Вишеградской группы были готовы учиться друг у друга и у своих ближайших западных соседей, другие страны с другим географическим расположением, по-видимому, сделали несколько иные выводы. Эстония, образцовая трансформирующаяся страна, указала, что будет применять более избирательную схему изоляции, которая будет менее вредна

11 Игорь Зевелев, «Постковидная слабость великих сил», Коммерсант, 31 мая 2020, по состоянию на 31 мая 2020, https://www.kommersant.ru/doc/4364043?from= main_9. 
для экономических интересов Таллинна, если пандемия коронавируса вернется. $^{12}$ Это явно урок, которому можно поучиться у Швеции, которая предпочла стремиться к «коллективному иммунитету», а не подвергаться изоляции, и применила эту схему относительно успешно.

В дополнение к вышесказанному, важным и часто вызывающим разногласие фактором был вопрос о том, сколько тестов на коронавирус могут провести разные страны. На это было несколько причин:

1. На раннем этапе была очевидная нехватка наборов для тестов. Затем, когда стали доступны дополнительные поставки, возникли сомнения в надежности комплектов для испытаний, импортированных из Китая.

2. Очевидно, что тесты напрямую не спасают жизни. Но без них могут быть приняты политические решения, которые могут нести огромный, неотъемлемый риск просчета.

3. Однако, если проводится мало тестов, многие случаи не отражаются в статистике, и поэтому статистику числа зараженных можно было держать на низком уровне. Это вызывало озабоченность, особенно в тех странах, где уровень смертности был высоким по сравнению с общим числом заболевших. По мере развития пандемии большинство стран ЦВЕ, казалось, осознавали важность тестирования и наличия надежной информации. Однако различия, имевшие место на ранних этапах, например, между Чехией и Венгрией, оставались. ${ }^{13}$

Менеджмент пандемии привлек внимание к государственным органам, ответственным за этот сектор. В некоторых случаях министрам приходилось брать на себя политическую ответственность за ситуации, к которым они не имели никакого отношения, таким как задержка выплаты премий медицинским работникам, или когда некоторые из них попадали под перекрестный огонь из-за своей высокой профессиональной совести, требуя всеобщего тестирования население столицы. ${ }^{14}$ В других странах последствия были более серьезными, например, в Венгрии, где министр, ответственный за здравоохранение, приказал освободить 36000 больничных коек (примерно 60 процентов от общего числа имеющихся); некоторые из них не были заняты,

12 "May Blog: Coronavirus in Estonia," Estonian World, May 31, 2020, по состоянию на 1 июня 2020, https://estonianworld.com/life/blog-coronavirus-in-estonia.

13 Относительно раннего отчета, смотри Shaun Walker and Christian Davies, "Lack of Testing Raises Fears of Coronavirus Surge in Eastern Europe," The Guardian, March 29, 2020, по состоянию на 16 мая 2020, www.theguardian.com/world/2020/ mar/29/lack-of-testing-raises-fears-of-coronavirus-surge-in-eastern-europe.

14 Относительно деталей, смотри анализ Matthew Rhodes and Valbona Zeneli, "COVID-19 and Southeast Europe," Security Insights 58, May 2020, по состоянию на 22 мая 2020, www.marshallcenter.org/en/publications/security-insights/covid-19and-southeast-europe-0, упоминая Болгарию и Румынию, соответственно. 
но многие были заняты, что привело к преждевременной или ненужной смерти пациентов. Позже эта жесткая мера была смягчена, и 12000 больничных коек были возвращены для использования пациентами без коронавируса. ${ }^{15}$ Когда правительство осознало, что избежать скандала будет трудно, министр по вопросам человеческих ресурсов был направлен в парламент с сообщением о том, что ни одна больница не была обязана освобождать больничные койки. Можно спросить, было ли это откровенной ложью, как заявила оппозиция. И если подумать, что случилось бы с директорами больниц, можно было бы сделать вывод, что это так. Однако если посмотреть на текст министерского поручения, то ситуация усложняется. Действительно, больницам было приказано освободить 60 процентов больничных коек к 15 апреля. Однако в третьем параграфе инструкции говорилось: «Все пациенты должны быть переведены в другое учреждение, если это оправдано потребностью пациента в уходе». ${ }^{16}$ Поскольку никто не стал переводить пациентов, нуждающихся в дальнейшем лечении, в другие больницы, было бы сложно решить, как министерство могло бы отреагировать, если бы больницы начали переводить тяжелых больных, не инфицированных COVID-19, которых нельзя было вернуть домой, в другие больницы. Важно отметить, что есть одна часть государственной структуры, которая работает достаточно хорошо, и она передает послания, которые не могут быть идентифицированы как противоречащие фактам.

Помимо обстоятельств, изложенных выше, полезно сделать вывод, что успех эффективной борьбы с таким кризисом, как пандемия коронавируса, зависит от нескольких простых вещей. Она требует своевременных решений, своевременных действий властей, а также честного и надежного общения. Как показал пример нескольких стран, также помогает единство политического класса, который отбрасывает предыдущие разногласия.

\section{Выводы}

Государства ЦВЕ противостояли пандемии коронавируса весной 2020 года лучше, чем многие другие страны, как в Европе, так и в мире в целом, которые наделены большими ресурсами и более серьезными секторами здравоохранения. Это было связано с различными факторами, включая раннюю

15 Anna Danó, "During Eight Days Hospitals Have to Vacate Approximately 36 Thousand Beds," Népszava, April 9, 2020, in Hungarian, по состоянию на 15 апреля, 2020, https://nepszava.hu/3074040_koronavirus-nyolc-nap-alatt-mintegy-36-ezer-agyatkell-kiuriteniuk-a-korhazaknak.

16 “Utasítás COVID-19 fertőzött betegek ellátására alkalmas ágykapacitás bővítésére [Instruction to expand bed capacity to care for COVID-19 infected patients]," Emberi Erőforrások Minisztériuma / Ministry of Human Capacities, IV/3220/2020/EFFHAT, April 7, 2020, по состоянию на 29 мая 2020. Доступно на www.portfolio.hu/ gazdasag/20200521/koronavirus-kasler-miklos-mondatat-sajat-levele-cafolja-meg433100 . 
реакцию правительств, поддержку населения, дисциплину наиболее уязвимых, пожилых людей, обилие больничных коек, а также то, что пандемия не поставила под угрозу возможности здравоохранения. Им повезло, поскольку в некоторых государствах региона были проблемы, в том числе небольшие материальные резервы и истощение профессиональных кадров в медицинской службе. Ни одна из стран ЦВЕ не пыталась «изобретать велосипед», и в отличие от таких государств, как Беларусь, Бразилия или Швеция, не последовала Sonderweg (особому способу). Большинство государств ЦВЕ пытались ограничить индивидуальные свободы до необходимой степени, а затем постепенно снимали ограничения, такие как на международные поездки в ЕС, в координации со своими соседями.

Остается неясным пока, усвоило ли каждое государство ЦВЕ уроки пандемии и сделало ли выводы для устранения таких критических недостатков, как удержание медицинских работников за счет улучшения оплаты и условий труда. Многие правительства начали рассматривать эти вопросы, но было бы преждевременно говорить о том, будут ли последующие действия, или политический компромисс приведет к размыванию необходимых решений. Без этих изменений некоторые страны ЕЭК могут столкнуться с серьезными проблемами, если пандемия вернется снова и станет более тяжелой, чем раньше.

\section{Отказ от ответственности}

Выраженные здесь взгляды являются исключительно взглядами автора и не отражают точку зрения Консорциума оборонных академий и институтов изучения безопасности ПрМ, участвующих организаций или редакторов Консорциума.

Издание Connections: The Quarterly Journal, том 19, 2020 осуществляется при поддержке правительства Соединенных Штатов.

\section{Об авторе}

Д-р Пал Дунай - профессор по вопросам НАТО и европейской безопасности в Центре им. Маршалла и научный консультант его курсов PASS, ESS-E и SES. Он был директором Академии ОБСЕ в период с 2014 по 2016 год, директором международного курса обучения по политике безопасности в Женевском центре политики безопасности (GCSP) с 1996 по 2004 год, а затем с 2007 по 2014 год, директором Венгерского института международных отношений в 2007 году и старшим научным сотрудником Стокгольмского международного института исследования проблем мира (SIPRI) с 2004 по 2007 год. E-mail: pal.dunay@marshallcenter.org. 